\title{
Integrierte Betrachtung von Streckenabschnitten und Knotenpunkte
}

Die integrierte Betrachtung von Streckenabschnitten und Knotenpunkten ist seit längerem eine Forderung aus der Wissenschaft, da sich die Elemente gegenseitig beeinflussen. So wird beispielsweise in (Richter 1993) dargelegt, dass auf Streckenabschnitten mit signalisierten Knotenpunkten ein anderes Fahrverhalten zu erwarten ist als auf Streckenabschnitten mit nicht signalisierten Knotenpunkten. In (Steinhauer et al. 2008) werden Streckenzüge aus Sicht des Verkehrsablaufes bewertet und auch hier stellte sich eine gegenseitige Einflussnahme dar. Die RAL (FGSV 2012) berücksichtigen diesen Umstand und bieten für die einzelnen Entwurfsklassen abgestimmte Querschnitte und Knotenpunkttypen mit jeweils abgestimmten Elementgrößen an.

Es sind daher schon in der Phase der Bedarfsplanung und der Linienfindung in Abhängigkeit von der Verbindungbedeutung und der daraus abgeleiteten Entwurfsklasse die Regelquerschnitte, die empfohlenen Elementgrößen sowie die Knotenpunkttypen und deren betrieblichen Elemente zu berücksichtigen. 